\title{
A avaliação da implementação de políticas públicas a partir da perspectiva neo-institucional: avanços e validade
}

\author{
Roberto Rocha*
}

\section{Resumo}

Este artigo tem como objetivo apresentar as linhas gerais de um modelo de avaliação da implementação de políticas públicas derivado da teoria neo-institucional. 0 modelo proposto busca estabelecer uma correspondência entre 0 momento de implementação da política e o processo de mudança institucional. A partir daí, são geradas análises fundamentalmente baseadas nos conceitos de dependência da trajetória e de custos de transação. A noção de dependência da trajetória é empregada no intuito de fornecer indícios a respeito dos fatores que sustentam a mudança institucional, ou seja, os elementos que constituem a base para a implementação da política. Já o conceito de custos de transação é utilizado como base de um esquema destinado a abordar os efeitos provocados pela implementação da política, proporcionando uma visualização do potencial transformador que os novos arranjos institucionais trazidos pela política implementada possuem sobre as práticas de governo. 0 modelo apresentado enfatiza a relevância da avaliação de políticas públicas inovadoras surgidas, principalmente, a partir de 1988 e destaca sua utilidade para a análise de políticas participativas.

Palavras-chave. : Políticas Públicas ; Implementação; Análise Neoinstitucional

\begin{abstract}
The article aims to sketch the general framework of a model for evaluation of policy implementation based on concepts drew from the neoinstitutional theory. It seeks to stablish a line between implementation and institutional change. From that on, analysis are developed upon the concepts of path dependence and transactions costs. Path dependence is employed in order to provide the tracks that sustained the process of institutional change and transaction costs sets the basis for identifying and evaluating the implementation effects, both stressing the transformtive potential carried by new institutional arrangements over governmental practices. The proposed model addresses the rising of innovative policies that emerged, mainly, since 1988 and highlights its use for participatory policy's analysis and evaluation.
\end{abstract}

Key words: Public Plolicy; Implementation; Neoinstitucional Analysis

\section{Introdução}

Este artigo visa discutir e propor as linhas gerais de um modelo de avaliação da implementação de políticas públicas, a partir de alguns conceitos e ferramentas analíticas oriundos da perspectiva neo-institucional.

Tal pretensão encontra justificativa na constatação da necessidade de ampliação e aprofundamento da produção teórica sobre os efeitos e impactos que as políticas públicas podem provocar sobre o planejamento e a gestão governamental. Parte-se do pressuposto de que o momento de implementação constitui a etapa em que antigos arranjos institucionais são substituídos e em que se abrem possibilidades de investigação a respeito das repercussões que os novos procedimentos e normas trazidos com a política pública poderão gerar.

No intuito de subsidiar o desenvolvimento e a proposição de tal modelo de análise focado na implementação, este artigo está estruturado da seguinte forma: 
- primeiro, aborda a relação entre o processo de descentralização impulsionado a partir de 1988 e o surgimento de inovações em políticas públicas, entendidas como relevantes objetos de avaliação;

- na sequiência, são apresentados alguns conceitos e noções fundamentais ligados ao "novo institucionalismo" e a políticas públicas, que servirão de subsídio para a proposição do modelo;

- a partir daí, a próxima etapa aplica esses conceitos e noções na avaliação da implementação de políticas públicas, apresentando as linhas gerais do modelo e alguns exemplos de sua aplicação;

- por fim, traça uma conclusão que visa identificar os possíveis avanços e a validade do modelo sugerido.

\section{Descentralização e inovações em políticas públicas}

A Constituição Federal de 1988 impulsionou e formalizou um processo de descentralização que, grosso modo, logrou ampliar a autonomia administrativa, política e financeira dos municípios, uma vez que estes passaram a ser tratados e reconhecidos como entes federativos. A partir dessa mudança constitucional, o poder local vem sendo submetido a transformações no que diz respeito ao seu papel, assumindo novas responsabilidades e experimentando a exploração de novas potencialidades, buscando equacionar, quase que de forma independente, os desafios impostos pelas necessidades de desenvolvimento social, político e econômico. A esse cenário, acrescenta-se o fato de que além da ampliação de competências e deveres, a descentralização preconizada por essa Constituição possibilitou a instauração paulatina de condições institucionais e políticas para uma atuação governamental mais democrática no nível local (FUNDAÇÃO JOÃO PINHEIRO, 2000).

Dessa forma, a confluência dos desafios enfrentados pelos governos locais com a possibilidade de intensificação da democracia vem abrindo caminhos para a instauração de novas institucionalidades que, em alguns casos, têm redefinido as ações entre Estado e sociedade. Tais novas institucionalidades emergem principalmente a partir da inventividade dos governos locais, que vêm demonstrando enorme capacidade de abordar velhos e novos problemas com soluções criativas e inovadoras. São soluções que tomam a forma de políticas públicas e vêm formando novos padrões de gestão governamental.

É possível dizer que parte considerável dessas políticas públicas inovadoras traz como marca uma orientação para uma maior incorporação da participação popular no processo de gestão e de tomada de decisão. Alguns estudos sobre inovações na gestão pública informam que, vistos em conjunto, os programas e projetos apontam para a ampliação da cidadania, aliada à busca por maior responsabilização na utilização dos recursos públicos. De forma geral, as inovações em políticas públicas têm sido caracterizadas pelo surgimento de novas áreas de atuação, novas formas de concepção das políticas e novas formas de gestão e processos (FARAH, 2000). Em todos esses aspectos é possível encontrarmos elementos ligados à questão da participação popular.

Em muitos casos, a intensificação da participação popular possui a capacidade de reformular o relacionamento entre Estado e sociedade, estabelecendo fundamentalmente a noção de parceria. Esse tipo de visão têm trazido importantes ganhos de produtividade e aperfeiçoamento da administração pública. Partindo dessa percepção, muitos governos que encaram a participação como partilha de poder na formulação e implementação de políticas públicas vêm buscando mecanismos capazes de institucionalizar os processos participativos, de modo a assegurar-lhes continuidade e eficácia, haja vista os exemplos dos conselhos gestores, orçamento participativo, planejamento participativo etc. (SOARES e GONDIM, 1998).

A institucionalização e implementação dessas políticas representam a incorporação de novidades ao conjunto de processos e procedimentos que conformam a administração pública tradicional. O caráter de novidade gera a necessidade de avaliação e construção de uma base informacional sobre a integração da política no ambiente institucional em que se insere. Além disso, a relevância da avaliação de inovações, tal como afirma Boschi (1999), parte da constatação de que em teoria política inexiste uma explicação adequada sobre como se

\footnotetext{
${ }^{1}$ No âmbito do programa "Gestão Pública e Cidadania” da Fundação Getúlio Vargas e da Fundação Ford.
} 
constroem novos desenhos institucionais na relação público-privado. Decorre também, e principalmente, da constatação de que uma vez implantados novos formatos para a produção de determinadas políticas, com o tempo, estes se consolidam como experiências consagradas, o que evidencia a carência de uma teoria consistente quanto à mudança institucional e o processo de institucionalização.

Daqui em diante, deveremos proceder à construção de um modelo de avaliação de políticas públicas que foque o momento de implementação. Para isso, deverá ser trabalhada a inter-relação entre o processo de implementação e a mudança institucional. A seguir, deverão ser revisados, de forma superficial, alguns conceitos e noções básicas da teoria neo-institucional e de políticas públicas.

\section{Noções preliminares}

\section{Aportes do novo institucionalismo}

De forma bem sucinta (GOODIN, 1997; MARCH e OLSEN, 1983; POWELL e DIMAGGIO, 1991; LANE, 1993; NORTH, 1990).é possível dizer que o novo institucionalismo e suas diversas escolas buscam a construção de uma visão mais elaborada acerca das formas pelas quais as instituições moldam a vida social (GOODIN, 1997), destacando que a organização da vida política possui uma enorme importância (MARCH e OLSEN, 1983).

A organização da vida política pode ser entendida como a adoção de mecanismos que proporcionam a estabilidade das decisões sociais, isto é, mecanismos que reduzem a incerteza do ambiente social e possibilitam aos diversos atores a construção de expectativas de comportamento por parte dos demais. Os neoinstitucionalistas buscam mostrar que a organização da vida política e do ambiente social ocorre através das instituições.

Por sua vez, o conceito de instituição é definido, em termos mais específicos, por cada uma das subcorrentes que compõem o novo institucionalismo - histórica, na escolha racional, ou política e econômica, e sociológica - (HALL e TAYLOR, 1996; GOODIN, 1997).Entretanto, grosso modo, há consenso quanto à definição de instituições como as "regras do jogo" numa sociedade (NORTH, 1990; JEPPERSON, 1991). Tal como afirma North (1990), as instituições são os constrangimentos humanamente impostos que moldam a interação humana. Esses constrangimentos definem tanto os limites e cursos de ação possíveis quanto o conjunto de oportunidades (NORTH, 1998). Por consequiência, a matriz institucional estrutura os incentivos e as condições para efetivação das trocas, sejam elas políticas, econômicas ou sociais.

As instituições reduzem a incerteza ao fornecer uma estrutura para a vida diária, como modelos morais ou cognitivos para interpretação ou ação. O indivíduo é visto como um ente profundamente imbricado no mundo das instituições, composto por símbolos, scripts e rotinas que oferecem um filtro para a interpretação da situação e da pessoa, a partir dos quais os cursos de ação são construídos (HALL e TAYLOR, 1996).

Instituições incluem qualquer forma de constrangimento que os seres humanos impõem para moldar a interação entre eles. Instituições podem ser constrangimentos formais (regras, normas, leis, tipicamente escritas) ou informais (convenções, códigos de conduta,

valores, símbolos, tipicamente não-escritos). Dessa forma, os constrangimentos institucionais incluem tanto o que os indivíduos são proibidos de fazer quanto sob quais condições devem fazer aquilo que lhes é permitido (NORTH, 1990).

A partir do que já foi colocado, uma noção importante que deve ficar clara é a de mudança institucional. A idéia de mudança institucional pressupõe um processo gradual e contínuo, através do qual as instituições evoluem e sofrem alterações. A mudança institucional consiste no processo através do qual arranjos institucionais anteriores deixam de estar em vigor, sendo substituídos por um novo conjunto de regras e procedimentos. É o momento em que novas instituições tomam o lugar de instituições antes estáveis. 
A análise do processo de mudança institucional nos conduz à busca por respostas para duas indagações fundamentais: qual é a origem ou que fatores sustentaram a mudança institucional ? E que efeitos poderão ser gerados a partir dessa mudança?

A reflexão sobre essas questões remete a dois conceitos de extrema relevância para o modelo de avaliação da implementação de políticas a ser proposto adiante. Trata-se dos conceitos de "dependência da trajetória" (path dependence) e de "custos de transação" (transaction costs).

Primeiramente, o conceito de dependência da trajetória, comumente associado ao novo institucionalismo histórico, mostra que as instituições se desenvolvem ao longo da história. Indica também que o processo através do qual as instituições de hoje são formadas não é somente relevante, como também, constrange as escolhas para o futuro. De certa forma, como observado por PUTNAM (1996), esse conceito nos faz pensar que o lugar a que se pode chegar depende do lugar de onde se veio, e que simplesmente é mais difícil chegar a certos lugares a partir de onde se está. O termo "lugar" pode ser entendido aqui como contextos históricos socialmente determinados que possuem a propriedade de estabelecer diferentes oportunidades e motivações. Para o agente social, seja indivíduo ou organização, adaptar-se às regras do jogo vigente ou ater-se às oportunidades institucionalmente dadas é sempre mais fácil do que modificá-las. Em outras palavras, uma vez estabelecido um dado caminho de desenvolvimento num determinado curso, a rede de externalidades, o processo de aprendizagem das organizações e os modelos de análise dos atores historicamente derivados atuam de forma a reforçar o curso iniciado.

Dessa forma, é possível compreendermos a relevância do conceito de dependência da trajetória como um elemento explicativo da mudança institucional. A partir de sua aplicação, podemos identificar as origens de instituições cuja implementação constitui um processo de substituição ou superação de arranjos institucionais anteriormente vigentes. Portanto, a noção geral do conceito de dependência da trajetória sugere a existência de uma forma de estreitamento conceitual do conjunto de opções disponíveis para os atores. Além disso, representa um elo ou conexão entre os processos de tomada de decisão ao longo do tempo.

Por sua vez, o conceito de custos de transação encontra suas raízes na tradição econômico-política do novo institucionalismo. Grosso modo, podemos dizer que os custos de transação são aqueles custos associados a todas as etapas envolvidas na efetivação de uma troca ou intercâmbio entre duas partes (AYALA, 199-). Na definição de Thrainn Eggertsson (apud BENHAM e BENHAM, 1998) os custos de transação incluem os custos dos recursos utilizados para criação, manutenção, utilização, alteração e assim por diante, de instituições e organizações. Furubotn e Richter (apud BENHAM e BENHAM, 1998) reconhecem duas possíveis variações:

- os custos de transação "fixos" - que constituem os investimentos específicos feitos para o estabelecimento dos arranjos institucionais; e

- os custos de transação "variáveis" - que envolvem os custos que dependem do número ou volume de transações.

Uma vez brevemente expostas essas definições, devem ser considerados os impactos da mudança institucional sobre os custos de transação. A implementação de novas instituições ou a simples reforma de instituições vigentes, conseqüentemente, produz mudanças nos termos que regulam a efetivação das trocas, como mudanças que possam afetar as negociações, os contratos e os direitos de propriedade, o que implicaria diretamente em renegociar e recontratar. Portanto, a mudança institucional altera os custos de transação, podendo muitas vezes provocar sua elevação em estágios iniciais (pós-reforma), uma vez que gera a necessidade (custos) de adaptação às novas regras (AYALA, 199-).

A aplicação dos conceitos de dependência da trajetória e de custos de transação no que se refere, respectivamente, à origem da mudança institucional e aos efeitos provocados por tal mudança, em um modelo de avaliação da implementação de políticas públicas, será trabalhada mais adiante. Por enquanto, ainda devem ser discutidas algumas noções básicas centrais para a presente proposta. 


\section{Políticas públicas e instituições}

Tal como afirma RUA (1997), políticas públicas podem ser entendidas como produtos ou outputs da atividade política, ${ }^{2}$ compreendendo o conjunto das ações estrategicamente selecionadas para implementar as decisões tomadas. A atividade política mencionada inscreve-se numa estrutura de poder que informa possibilidades e formas de interação entre os atores. Essas interações estão restritas a um universo marcado por dificuldades em relação à definição dos problemas e competências, seja por construções sociais da realidade que se convertem em referenciais para aqueles que pressionam em busca de uma ou outra solução, seja por idéias utilizadas aqui e ali para provocar mudanças nas preferências e alternativas, como também por "comunidades epistêmicas"3 que trabalham de forma conjunta para utilizar seus conhecimentos como recurso no jogo da tomada de decisões (SUBIRATS \& GOMÀ, 1998).

Nesse ambiente, atores, com interesses e recursos distintos, envolvem-se em interações diferenciadas, com pautas de jogo provavelmente distintas em cada política. Isso gera redes de interações, comunidades e instituições que são incorporadas ou que apenas servem de marco para o processo de elaboração, formação e implementação das políticas públicas. Daí, a política pública concreta resultaria, na visão de Kingdon (apud SUBIRATS e GOMÀ, 1998), da abertura de uma "janela" (policy window), produto da convergência momentânea dos problemas, das alternativas de políticas públicas e do processo político. Tudo isso, num contexto constituído a partir de fatores estruturais e institucionais.

A partir dessas sucintas considerações a respeito do macrocontexto no qual as políticas públicas se inserem, deve-se proceder ao estabelecimento de uma relação fundamental para a proposição do modelo de avaliação. Trata-se da relação entre políticas públicas e instituições. Uma política pública, seja qual for, envolve, cria, mantém e muda instituições. Isto é, surge a partir da articulação de um aglomerado de instituições. Acredita-se que uma política pública envolva conjuntos de regras e procedimentos, na medida em que possui objetivos a serem alcançados e que os busca através da definição de metodologias que instruem processos e definem maneiras de se desempenhar certas ações. Além disso, políticas públicas envolvem organizações, desde as ligadas a sua formulação até aquelas relacionadas a sua operacionalização. Sendo assim, tanto os frutos de arenas institucionais quanto as partes que as constituem representam elementos constritores destes e/ou de outros ambientes organizacionais.

Portanto, concordar que uma política pública envolve e se constitui a partir da articulação de um aglomerado de instituições nos leva a constatar que as suas etapas de implementação e manutenção possuem a capacidade de influenciar os resultados políticos, uma vez que incorporam elementos capazes de moldar a identidade, o poder e a estratégia dos atores. Sendo assim, podemos inferir que uma política pública é capaz de moldar (influenciar) comportamentos na medida em que, muitas vezes, as instituições que ela envolve atuam de forma a restringir os cursos de ação possíveis, além de incutir, num processo freqüentemente gradual, novos valores orientadores de novas práticas.

\section{Estabelecendo uma perspectiva neo- institucional na avaliação da implementação de políticas públicas}

O novo institucionalismo apresenta uma série de conceitos e ferramentas analíticas que podem proporcionar uma avaliação de política pública muito rica, considerando desde os aspectos internos da política até aqueles relacionados ao ambiente externo e aos atores envolvidos. Partindo do princípio de que uma política pública envolve e se constitui a partir de um aglomerado de instituições ou arranjos institucionais, podemos dizer que o seu processo de implementação constitui um momento de mudança institucional. Isto é, a implementação de uma política pública, tendo em vista os arranjos institucionais por ela trazidos, representará a superação ou a mera substituição de instituições anteriormente vigentes. Além disso, constituirá a adoção de novas regras e

\footnotetext{
${ }^{2}$ A autora define a política como o conjunto de procedimentos formais e informais que expressam relações de poder e que se destinam à resolução pacífica dos conflitos quanto a bens públicos.

${ }^{3}$ Esse conceito "pretende descrever o conjunto de profissionais ou técnicos que compartilham os mesmos critérios e valores diante de dilemas e conflitos sociais instalados". Tais indivíduos e grupos "crêem no que defendem e trabalham para que suas idéias influenciem e tenham efeitos sobre a política ou políticas concretas" (SUBIRATS e GOMÀ, 1998).
} 
procedimentos; portanto, irá gerar novas oportunidades e constrangimentos que, de formas distintas, causarão impacto no comportamento dos atores envolvidos.

Como já enunciado, um dos pontos mais valiosos da análise da mudança institucional diz respeito a uma compreensão mais aprofundada das questões ligadas aos fatores que sustentaram a mudança e aos efeitos provocados por ela.

A aplicação do conceito de dependência da trajetória permite explicar as origens da mudança institucional. Ao mesmo tempo, permite identificar e investigar os elos componentes da cadeia de decisões que interliga passado, presente e futuro. $\mathrm{O}$ emprego desse conceito na avaliação de políticas públicas e das instituições envolvidas permite perceber que certas trajetórias observadas ao longo dos processos de tomada de decisão governamental estão condicionadas por escolhas e decisões anteriores. Uma vez tomadas, tais decisões apresentam estabilidade no futuro, na medida em que o curso estabelecido tende a ser reforçado. Por tal motivo, podemos dizer que políticas públicas e suas instituições corporificam trajetórias históricas e momentos decisivos. Por isso, acabam por representar o desfecho de processos históricos evolutivos de restruturação dos arranjos institucionais vigentes. O que ocorre antes condiciona o que ocorre depois. Formuladores de políticas públicas podem definir os aspectos institucionais centrais - como a metodologia - de uma determinada política, mas não o fazem em circunstâncias e contextos que eles mesmos criaram. Além disso, suas escolhas influenciarão as regras e o conjunto de opções disponíveis, entre as quais seus sucessores atuarão.

A aplicação da noção de dependência da trajetória para a explicação do processo de implementação de uma dada política pública - em analogia ao processo de mudança institucional - pode ocorrer de duas formas:

- através da investigação e mapeamento histórico das políticas públicas implementadas anteriormente e das instituições relacionadas a elas;

- por meio da análise da influência recíproca entre instituições (e políticas públicas) e ideologia.

A primeira forma de aplicação do conceito de dependência da trajetória constitui um esforço que pode gerar um conjunto de informações capaz de apontar a trajetória a ser seguida, uma vez que o levantamento dos eventos e arranjos institucionais passados pode indicar aqueles elementos que reforçam a permanência num dado caminho. As políticas públicas implementadas no passado, seja recente ou não, são a base para as políticas que vierem a ser implementadas no presente e no futuro. A implementação e funcionamento das políticas anteriores acabam por gerar um processo de aprendizagem organizacional, o qual ocorre através da internalização de novos princípios, reforço àquelas iniciativas bem sucedidas e repúdio àquelas que produziram resultados piores. Além disso, a existência de uma política pública corresponde à percepção de toda uma sustentação técnica e administrativa que envolve pessoal, estrutura física e administrativa. Tais elementos - aprendizado organizacional e sustentação técnico-administrativa - vão constituindo, num processo histórico e incremental, um ambiente propício e receptivo para um dado conjunto de novas iniciativas, assim como, um terreno infértil para diversas outras ações.

Um estudo recentemente elaborado sobre o processo de mudança institucional impulsionado pelo orçamento participativo em Belo Horizonte (PIRES, 2001) buscou identificar e analisar as políticas públicas e decisões governamentais implementadas anteriormente. Trata-se :

- de um dispositivo na Lei Orgânica do município destacando que a administração da cidade se faria envolvendo instâncias de participação popular;

- do Prodecom (Programa de Desenvolvimento de Comunidades);

- do Prodasec (Programa de Ações Socioeducativas e Culturais para as Populações Carentes do Meio Urbano);

- do Propar (Programa Participativo de Obras Prioritárias);

- da subdivisão em administrações regionais e criação dos conselhos comunitários. 
De forma geral, a avaliação dessas iniciativas precedentes concluiu que, gradualmente, vinha ocorrendo no município um processo de reorientação das ações de sua administração, no sentido de uma intensificação de sua permeabilidade à participação e do processo de descentralização. Além disso, foi possível perceber que, na dimensão social, as ações governamentais analisadas foram capazes de promover uma ampliação da capacidade associativa e de mobilização das comunidades. Com isso, verificou-se, no período, a emergência de arenas políticas que colocavam a população e os técnicos da prefeitura face a face, estimulando o debate, a negociação, a transparência e o controle público.

Nesse sentido, é possível falarmos de um processo de empowerment ou construção de habilidades e capacidades, tanto no plano da cidadania quanto no de governo. Esse processo acabou por constituir um conjunto de condições prévias favoráveis para a implementação do orçamento participativo em Belo Horizonte. A análise das ocorrências anteriores possibilitou perceber que a articulação com instâncias organizadas da sociedade já estava presente em vários setores da máquina pública municipal. E, mesmo que as ações do passado não tivessem propiciado uma mudança efetiva do estilo de governar, acabaram criando as condições institucionais para tal. Logo, é possível dizer que o orçamento participativo em Belo Horizonte já contava com uma base para sua implementação, formada principalmente a partir de um processo de aprendizagem organizacional e de uma sustentação técnica e administrativa "herdada", envolvendo pessoal, estrutura física e administrativa.

A segunda forma de aplicação da noção de dependência da trajetória na avaliação da mudança institucional diz respeito à formulação de explicações a partir da análise da influência recíproca entre instituições (e políticas públicas) e ideologia. As percepções e ideologias dos atores são frutos de um estreitamento conceitual proporcionado pela existência de instituições. Ao mesmo tempo, percepções e ideologias atuam como fontes de inspiração para a reconfiguração institucional. Numa aplicação mais direta ao caso de políticas públicas, tal influência recíproca é evidenciada - de acordo com Hall e King (apud THELEN e STEINMO, 1992) - a partir da percepção de que as estruturas institucionais definem os canais e mecanismos através dos quais novas idéias são traduzidas em políticas. Assim como a partir da constatação de que as novas idéias e pressupostos éticos, morais e técnicos influenciam o desenho, metodologia e a forma de implementação de novas políticas públicas e das instituições ligadas a essas estruturas institucionais.

SUBIRATS e GOMÀ (1998) chamam atenção para o fato de que tais idéias e pressupostos constituem o referencial de uma política. Isto é, representam a forma como estão organizadas as percepções dos atores em relação ao sistema. Essas percepções, ou o referencial de uma política, influenciam de maneira decisiva os critérios de julgamento e formação de preferências, nas pautas de interação com os demais atores, como também na avaliação tanto do processo de implementação quanto dos impactos de uma política. $\mathrm{O}$ compartilhamento de percepções ao nível de grupos organizados acarreta a formação de comunidades epistêmicas. Uma vez formado, esse grupo de indivíduos que compartilham os mesmos valores e princípios em relação a determinadas situações atua de forma a influenciar a formação de políticas públicas concretas.

A título de exemplo, o referido estudo sobre a implementação do orçamento participativo em Belo Horizonte adotou como hipótese explicativa para a origem e emergência da política, o reconhecimento do Partido dos Trabalhadores (PT) e seus aliados locais como uma dessas comunidades epistêmicas. Isso porque é constatada, em termos concretos, uma forte relação entre o desenvolvimento da política do orçamento participativo e o ideário e as ações do PT. Tal relação se justifica pelos princípios orientadores adotados pelo partido "democratização no processo de tomada de decisão" e "inversão de prioridades" -, como também pela constatação da abertura de canais institucionais de participação (conselhos e orçamentos participativos, dentre outros) nos diversos governos administrados pelo partido, principalmente, a partir de 1988 (ABERS, 2000). Tal como afirma GENRO (1997), o fato de o partido se firmar no cenário político nacional e assumir a direção de frações do Estado, possibilita-lhe implementar princípios ético-políticos e programáticos que constituem sua visão de mundo. É a partir desse cenário, marcado pela construção de uma base consensual no plano das idéias e que passa a influenciar as ações concretas, que a política do orçamento participativo emergiu em Belo Horizonte em meados de 1993. 
A aplicação do conceito de dependência da trajetória pode oferecer interessantes indícios em relação aos possíveis fatores que sustentam uma mudança institucional. Além disso, a noção de dependência da trajetória se torna um instrumento conceitualmente relevante, pois mostra que mesmo as iniciativas inovadoras, em termos de políticas públicas, surgem a partir das motivações e oportunidades fornecidas pela estrutura institucional. Sendo assim, elas carregarão consigo elementos da estrutura anterior que atuarão de forma a reforçar tendências já há algum tempo iniciadas.

Como demonstrado, a aplicação desse conceito pode ser feita através de um mapeamento histórico e de uma análise sobre como estão organizadas as percepções dos atores envolvidos em relação àquela determinada situação. A partir desses dois caminhos torna-se possível não só constatar a dependência - "o lugar a que se pode chegar depende do lugar de onde se veio e, simplesmente, é mais difícil chegar a certos lugares a partir de onde se está" (PUTNAM, 1996) - como também em qual trajetória ela ocorre. Identificar a trajetória se torna extremamente importante quando olhamos para o futuro, buscando antever e entender os possíveis efeitos e mudanças que se processarão. Pois, como Montesquieu (apud PUTNAM, 1996) observou, "primeiro a política molda as instituições, mas posteriormente as instituições moldam a política".

Abordando, então, a questão relativa aos efeitos provocados pela mudança institucional, procede-se à aplicação do conceito de custos de transação na avaliação de políticas públicas.

Um processo de mudança institucional, que provoca a reconfiguração da estrutura de oportunidades e constrangimentos, conseqüentemente, acaba por alterar os custos de transação. Ou seja, aqueles custos que correspondem às condições para a viabilização de uma troca ou acordo entre partes. Parte-se do pressuposto de que uma política pública pode ser vista como um acordo ou troca. E para que os custos envolvidos nessa troca possam ser minimamente visualizados, é imprescindível a identificação da troca ou acordo que caracteriza a política. De forma geral, as partes envolvidas serão o poder público e os cidadãos. Os objetos de troca serão, do lado do cidadão, a contribuição tributária e mais alguns recursos por ele despendidos (por exemplo, a sua participação), e do lado do poder público, o conjunto da ação governamental. De forma mais específica, podemos citar o exemplo de troca envolvida no orçamento participativo de Belo Horizonte, que é o seguinte:

- a Prefeitura de Belo Horizonte abre mão do seu direito ou competência constitucional de produzir reservadamente todo o orçamento municipal, concedendo parte dele à decisão popular. Por sua vez, a participação popular atua para a prefeitura como uma forma de diagnóstico de demandas e necessidades, além de gerar a co-responsabilização ${ }^{4}$ dos participantes pelos resultados de tal atuação política, e de incrementar as bases de legitimidade do governo;

- a população contribui com seu envolvimento no processo orçamentário, uma vez que através da participação poderá defender e definir diretamente suas necessidades e prioridades.

A partir da explicitação da troca, a identificação dos custos da transação deverá apontar todos os requisitos e condições necessárias para que a troca seja realizada ou a política executada. Esses custos estarão subdivididos em "custos de informação" - ligados à obtenção, processamento e distribuição de informação para o planejamento, desenho institucional e tomada de decisão, além de envolver os custos de aprendizagem organizacional e capacitação de pessoal -, em "custos de manutenção" - relativos à manutenção das organizações, monitoramento e avaliação de processos e resultados -, e em "custos de imposição" (enforcement) - ligados à imposição e garantia dos resultados da troca ou do acordo e aos custos relacionados à renovação da troca e seus termos.

No intuito apenas de ilustrar o que está sendo proposto, são apresentados alguns itens desses tipos de custos de transação identificados para o orçamento participativo de Belo Horizonte:

\footnotetext{
${ }^{4}$ A compreensão que se espera ter do termo "co-responsabilização" pode ser ilustrada a partir da seguinte itação: "se a comunidade definiu como prioritário o alargamento de uma rua, o programa assume todos os custos materiais e a comunidade assume os custos políticos e sociais da pressão dos interesses privados prejudicados com a produção daquele bem coletivo" (FUNDAÇÃO JOÃO PINHEIRO, 1992).
} 
- "custos de informação" - são aqueles envolvidos no desenvolvimento da metodologia, do ambiente organizacional (funções, papéis e atribuições) e dos procedimentos; os relativos à coleta de dados nos órgãos responsáveis pela execução da política, nas assembléias populares e nas comissões de fiscalização; os custos envolvidos no tratamento estatístico desses dados; os relacionados à produção de informativos; os custos com treinamentos iniciais (tanto do corpo técnico e burocrático quanto dos participantes), através de seminários de sensibilização; e os custos de capacitação de lideranças populares, por meio da realização de cursos e reuniões.

- "custos de manutenção" - envolvem a implantação e manutenção das estruturas responsáveis pela coordenação de todo o processo orçamentário participativo, incluindo custos fixos e variáveis; são aqueles ligados ao processo de negociação representado pela fragmentação organizacional das agências públicas municipais e na negociação com as instâncias de participação popular e controle público; e os custos relativos ao monitoramento dos custos incorridos por essas organizações.

- "custos de imposição" (enforcement) - são ligados à manutenção das estruturas organizacionais (incluindo custos fixos e variáveis), que correspondem às instâncias de participação e controle público do orçamento participativo (exemplo: as Comissões Regionais de Fiscalização das Obras do Orçamento Participativo Comforças); referem-se também aos custos com a negociação dessas organizações e instâncias de participação popular com a prefeitura, incluindo a preparação e realização de reuniões; além dos custos de processamento das decisões nelas tomadas.

A reflexão a respeito da noção de custos de transação, aplicada à avaliação de políticas públicas, possibilita a identificação ou mapeamento dos diversos grupos e organizações envolvidos (stakeholders), bem como permite visualizar a distribuição (entre eles) dos encargos relativos à política. A realização dessa tarefa pode fornecer subsídios muito importantes para o desenvolvimento e estabelecimento de mecanismos e espaços de concertamento e negociação - assim como suas regras de funcionamento - entre os diversos atores envolvidos.

A noção de custos de transação pode apresentar ainda maior utilidade quando aplicada a políticas públicas participativas, na medida em que é uma ferramenta analítica que torna possível o tratamento e a incorporação de fatores não mensuráveis, presentes na troca (ou política pública). Numa política participativa, a busca por uma melhor apropriação de todos os custos envolvidos no processo não é apenas relevante, mas também constitui um considerável desafio. Possuir uma noção ampla e mais completa a respeito dos custos e condições básicas para a viabilização da política possibilitaria um substancial aprimoramento da discussão entre a administração e a população, tornando o processo ainda mais claro e transparente, e proporcionando uma negociação mais franca e objetiva.

Entender os custos envolvidos na efetivação de uma troca, ou na implementação e manutenção de uma política pública, toma grande relevância quando compreendemos que os custos de transação são determinados pela estrutura institucional vigente. Pois, de acordo com North (1990), é o arranjo institucional que determina como cada um daqueles três conjuntos de custos de transação podem ser processados e absorvidos pelos atores envolvidos. Tal constatação nos leva a inferir, portanto, que a mudança institucional altera os custos de transação. Isso quer dizer que a implementação de uma política pública tem a capacidade de alterar, em algum nível, os termos da troca, provocando alterações nos custos de transação.

A mudança institucional pode vir a reconfigurar a estrutura de incentivos e recompensas colocada para os atores. Nesse novo arranjo, uma possível elevação dos custos de transação pode derivar:

- da capacidade institucional e da reação do implementador diante das novas oportunidades e constrangimentos;

- de problemas de natureza política (conflitos ideológicos, partidários, de poder etc.); e

- da resistência e boicote por parte de grupos afetados pela política (seja na sociedade ou no aparato governamental). 
Por sua vez, a alteração ou aumento dos custos de transação produz efeitos sobre o padrão de comportamento dos atores envolvidos com as instituições resultantes da efetivação da troca. Como salienta North (1990), tal fato acabará por incentivar indivíduos e organizações a atuarem de forma a maximizar seus interesses através da captura de novas oportunidades na estrutura de incentivos reformulada, e através do desenvolvimento de novas regras que reduzirão os custos de transação, a partir do aprimoramento do processo de troca. Esse esquema analítico é baseado no modelo de comportamento estratégico dos atores. O novo institucionalismo em especial sua subcorrente na escolha racional - parte do pressuposto de que os atores possuem um conjunto fixo de preferências e atuam visando maximizar seus interesses. Na escolha racional, os institucionalistas estabelecem uma série de modelos de interação estratégica entre os atores envolvidos. Esses modelos ganham utilidade na medida em que permitem, mesmo que de forma hipotética, o estabelecimento de previsões dos cursos de ação a serem adotados pelos atores, quando envolvidos numa situação problemática ou conflituosa. No caso da análise de políticas públicas, esse esquema possibilita uma visão mais clara acerca dos interesses e conteúdos que se apresentam como relevantes na esfera de discussão política.

O aprimoramento dos termos da troca - alcançado através de mudanças que tornem o processo mais estável e confiável, com vistas à redução dos custos de transação -, acaba por coincidir com um processo de desenvolvimento e evolução da política pública. Muitas vezes, esse processo se manifesta em alterações na metodologia operacional da política e nos seus aparatos periféricos e de suporte, revelando um aprendizado no decorrer da implementação da política. Freqüentemente, tais mudanças informam e introjetam novas práticas nas organizações em que ocorrem.

Uma das manifestações do que se pretende descrever aqui é a constatação de que, em alguns casos, políticas públicas participativas tendem a intensificar a atividade de planejamento no interior dos governos, ou pelo menos no interior das agências diretamente ligadas à política. Isso porque a abertura do canal de participação e o conseqüente início de um fluxo de informações entre a administração pública e o cidadão impõem ao governo não só a necessidade de estabelecer um diálogo aberto e transparente, como também, de organizar informações, metas, planos e prazos. Somente a partir de uma "pré-programação" das atividades rotineiras e críticas é que o governo pode assumir compromissos credíveis com a população; compromissos que possam ser cumpridos em termos de qualidade, quantidade e prazo. A necessidade de manutenção da legitimidade impede que se prometa o que não se pode cumprir e, nesse sentido, é crucial planejar o levantamento de informações relevantes.

Políticas públicas participativas - tendo em vista que são capazes de construir arenas de negociação que envolvem o governo, os órgãos executivos e os cidadãos - somente perduram e se consolidam como práticas, se forem capazes de levar a compromissos e acordos efetivos. Além disso, sua continuidade e consolidação também dependem de que esses acordos e compromissos sejam cumpridos a contento por ambas as partes, numa atmosfera de parceria e cooperação, levando em conta os conflitos inerentes a esses tipos de relação.

O cumprimento dos acordos por parte do poder público esbarra na morosidade e nas deficiências de seu aparato. É nesse sentido que a atividade de planejamento passa a ser vista como fundamental para o aumento da eficiência dos órgãos e agências públicas. Além disso, a intensificação da atividade de planejamento também pode proporcionar uma maior transparência das ações e decisões públicas, uma vez que é capaz de fornecer critérios e objetivos predefinidos que orientarão essas ações e decisões.

No estudo mencionado anteriormente, sobre o orçamento participativo em Belo Horizonte (PIRES, 2001), a hipótese que relaciona a incorporação da participação popular com a intensificação do planejamento pôde ser verificada. Partindo das mesmas premissas e pressupostos do modelo de avaliação aqui proposto, o estudo visou identificar e analisar os efeitos que a implementação da política do orçamento participativo provocou na dinâmica de planejamento da Prefeitura de Belo Horizonte. Os diversos efeitos identificados foram agrupados em dois conjuntos:

- captação e qualificação de demandas; e

- operacionalização e organicidade. 
O primeiro envolvia as atividades destinadas à constituição de um aparato capaz de colher e selecionar as reais prioridades ou ações mais necessárias, num contexto de abundância de demandas e recursos escassos, de forma a incorporá-las num referencial de atuação política lógico e sustentável. O segundo englobava ações que tratam do processo de transformação de prioridades selecionadas em ações viáveis, constituindo o aparato capaz de transformar demandas sociais em ações governamentais concretas, através da inserção dessas prioridades no ambiente organizacional da prefeitura, tornado-as metas de execução para as diversas agências municipais.

Com base nas informações disponíveis, tal estudo pôde concluir que a dinâmica do orçamento participativo e as alteração que este sofreu em relação a sua metodologia e funcionamento tornaram imprescindível programar antecipadamente a atuação dos órgãos da prefeitura. $\mathrm{O}$ atendimento das demandas e o cumprimento dos compromissos assumidos pela administração junto à população fez com que a capacidade operacional e gerencial da prefeitura tivesse que ser ampliada, o que foi conseguido através do planejamento. Mais do que isso, a dinâmica de funcionamento do orçamento participativo e das instituições que o compõem atuaram de forma a influenciar uma cultura de planejamento transparente, objetiva, impessoal e baseada em critérios estáveis e predefinidos.

\section{Conclusão}

O arcabouço teórico do novo institucionalismo se revela muito rico quando aplicado à avaliação de políticas públicas, pois gera interessantes possibilidades de análise, principalmente, no que diz respeito ao estudo do momento de implementação da política. Ao tratar o momento de implementação como um processo de mudança institucional, a perspectiva neo-institucional permite analisar de forma consideravelmente densa:

- as bases sobre as quais emergem as políticas atuais, tanto a partir de uma ênfase sobre o processo histórico que as precede, quanto da atribuição de grande relevância ao papel das idéias na sua formação;

- os custos de transação envolvidos numa política pública, permitindo a verificação das condições básicas necessárias para a viabilização de uma interação entre Estado e sociedade, nesses moldes;

- a motivação para o empreendimento de esforços visando aprimorar os termos da troca envolvida na política pública, a partir da visualização dos custos de transação. Esse processo de aprimoramento resulta na alteração de normas e procedimentos que, por sua vez, influenciam o comportamento dos atores, tanto no Estado quanto na sociedade.

O fato de o modelo proposto ser capaz de abordar tais aspectos faz com que ele seja um instrumento capaz de fornecer respostas a indagações como: terá o processo de mudança institucional modificado as identidades dos atores políticos, redistribuído recursos políticos e incutido novas normas? E de que modo as novas instituições, instaladas a partir da implementação da política, influenciaram as práticas de governo?

Além disso, como o processo de avaliação de políticas públicas abre a possibilidade de interação entre diversas áreas de conhecimento, a utilização de um aparato teórico interdisciplinar, como o do novo institucionalismo, torna-se interessante pela oportunidade de apreensão da potencialidade de cada uma de suas subcorrentes. Cada uma das suas ramificações parece revelar dimensões diferentes e particulares do comportamento humano e dos efeitos que as instituições podem ter sobre ele. Em muitas situações, a possibilidade de cruzamentos entre essas distintas visões, como o emprego de conceitos de diferentes correntes, pode gerar análises bastante densas e interessantes. 


\section{Referências bibliográficas:}

ABERS, R. Learning democratic practice: distributing government resources through popular participation in Porto Alegre. In: FREIRE, M.; STREN, R. (Eds.). The challenges of urban government: readings on policy and practice. Washington: World Bank Institute, 2000.

AYALA, J. E. Una teoria neoinstitucionalista del estado. In: AYALA, J. E. Mercado, elección pública y instituiciones. Unam [199-].

BENHAM, A.; BENHAM, L. M esuring the costs of exchange. In: Annual Meeting of the International Society for the New Institutional Economics, 2, 1998. Proceedings... Universidade de Paris, 1998.

BOSCHI, R. R. Governança, participação e eficiência das políticas públicas: exames de experiências municipais no Brasil. In: MELO, M. A. (Org.). Reforma do estado e mudança institucional no Brasil. Recife: Fundação Joaquim Nabuco, 1999.

FARAH, M. F. S. Governo local, políticas públicas e novas formas de gestão pública no Brasil. (Curso de Gestão Urbana e de Cidades) Escola de Governo, Fundação João Pinheiro. WBI. PBH. ESAF. IPEA. 2000.

FUNDAÇÃO JOÃO PINHEIRO. CEPS. Pesquisa de saneamento ambiental e saúde pública: avaliação do Prodecom. Belo Horizonte, 1992. V.1.

Escola de Governo. 0 processo de implementação e gestão de políticas sociais sob a ótica dos conselhos: 0 caso das políticas de assistência social e de infância e adolescência em municípios mineiros. Belo Horizonte, 2000. 136p. Relatório de pesquisa.

GENRO, T. Combinar democracia direta e democracia representativa. In: PALOCCI, A. et. al. Os desafios do governo local: o modo petista de governar. São Paulo: Ed. Fundação Perseu Abramo, 1997.

GOODIN, R. E. (Org.). The theory of institutional design. Cambridge University Press, 1997.

HALL, P. A.; TAYLOR, R. C. R. Political science and the three new institutionalisms. Political Studies, 1996.

JEPPERSON, R. Institutions, institutional effects and institutionalism. In: POWELL, W.; DiMAGGIO, P. The new institutionalism in organizational analysis. Chicago: The University of Chicago Press, 1991.

LANE, J-E. The public sector - concepts, models and approaches. Londres: Sage Publications, 1993.

MARCH, J. G.; OLSEN, J. P. The new institutionalism: organizational factors in political life. American Political Science Review , n.78, 1983.

NORTH, D. C. Institutions, institutional change and economic performance. Nova lorque: Cambridge University Press, 1990. Press, 1998

Five propositions about institutional change. In: KNIGHT, J.; SENED, I. (Ed.). Explaining social institutions. University of Michigan

PIRES, R. R. C. Orçamento participativo e planejamento municipal: uma análise neo-institucional a partir do caso da Pref eitura de Belo Horizonte. 2001. Monografia (Curso Superior de Administração Pública) - Escola de Governo, Fundação J oão Pinheiro, Belo Horizonte.

POWELL, W.; DiMAGGIO, P. The new institutionalism in organizational analysis. Chicago: The University of Chicago Press, 1991.

PUTNAM, R. D. Comunidade e democracia: a experiência da Itália moderna. Rio de Janeiro: Ed. Fundação Getúlio Vargas, 1996. 260p.

RUA, M. G. Análise de políticas públicas: conceitos básicos. Programa de Apoio à Gerência Social no Brasil -BID, 1997.

SOARES, J. A.; GONDIM, L. Novos modelos de gestão: lições que vêm do poder local. In: SOARES, J. A.; CACCIA-BAVA, S. (Orgs.). Os desafios da gestão municipal democrática. São Paulo: Ed. Cortez, 1998.

SUBIRATS, J.; GOMÀ, R. (Orgs.). Políticas públicas en España: contenidos, redes de actores y niveles de gobierno. Barcelona: Ed. Ariel, 1998. 442p.

THELEN \& STEINM O (Ed.). Structuring politics: historical institutionalism in comparative analysis. Nova lorque: Cambridge University Press, 1992. 